\title{
UTILIZAÇÃO DA TERMOGRAFIA PARA ANÁLISE DE PATOLOGIAS EM OBRAS DE ARTE ESPECIAL
}

Jordyson Nunes de Lima ${ }^{(1)}$ (jordysonnunes@gmail.com), Fernando Hayne Klanovichs ${ }^{(2)}$

(fernandohayne@gmail.com), Gutemberg Faria Rios ${ }^{(3)}$ (abemec@abemec-df.org), Henrique Jorge Nery de Lima(4) (hjnery@gmail.com)

\footnotetext{
${ }^{(1)}$ Centro Universitário do Distrito Federal(UDF); Graduando em Engenharia Civil (2)Centro Universitário do Distrito Federal(UDF); Graduando em Engenharia Civil

(3) Associação Brasileira de Engenheiros Mecânicos (ABEMEC-DF); Presidente

(4) Universidade de Brasília (UNB); Mestre em Estruturas e Construção Civil
}

RESUMO: O estudo apresenta o cadastramento de manifestações patológicas dos viadutos de concreto armado das "tesourinhas" do eixo L e W, das quadras 11/12 da Asa Norte (Brasília DF). Foi realizada uma análise visual e termográfica de forma qualitativa, utilizando equipamentos para identificar a radiação por infravermelho transmitida pelo corpo estrutural. Desta forma, entende-se que existem duas maneiras de realizar a técnica da Termografia Infravermelho (TI): ativa e passiva. Neste trabalho foi feita a análise passiva, pois é uma técnica que não possui o estimulo "artificial" de energia, apenas aproveita a irradiação solar na estrutura. Como a metodologia da TI é um procedimento novo na construção civil e tendo consciência dos benefícios desta técnica, este trabalho tem como foco validar e aprimorar esse método em Obras de Artes Especiais (OAEs). Posteriormente, busca-se conscientizar a população sobre a extrema importância da realização de manutenções, por se tratar de situações de riscos à saúde e segurança do cidadão. Os resultados demonstram que a técnica termográfica em obra de arte especial é válida. Todavia, como todo método pode ser aprimorado, esta metodologia pode ser constantemente estudada e testada para apresentar, no futuro, uma maior facilidade na demonstração dos resultados.

PALAVRAS-CHAVE: Termografia Infravermelho, Viadutos, Manifestações patológicas.

\section{TERMOGRAPHIC USE WITH PATHOLOGIC ANALYSIS ON SPECIAL ARTWORK}

This study shows the registration of pathological manifestations of reinforced concret viaducts of the $L$ and W axis, onthe 11/12 block of "Asa Norte" in Brasilia .It was done a visual and termographic analysis on a qualitative way, using equipaments to identify the radiation of infra-red transmitted bt the structural body. Thus, it is known that exists two ways to perform the Infra-red Termography (IT) tecnique: active e passive. In this project it was made the passive analysis, because it is a technique that doesn't have the artificial energy incentive, it just use the sun irradiation in the structure. As that the IT methodology is a new procedure in the civil construction and knowing about the benefits of it, this study focuses on validating and improving this method in Special Artwork (SA). Then, it wants to aware the population about the extreme importance of maintenance, because it's about health and safety risk situations for the citizens. The results shows that the Special Artwork termographic technique is valid. However, as every method can be improved, this methodology can be constantly studied and tested to show, in the future, a easier demonstration of the results. 


\section{$\mathrm{XIX}$ \\ CIONEMI}

|Keywords: Infra-red Termographiv, Viaduct, Pathologic manifestation.

\section{INTRODUÇÃO}

A Termografia é umas das técnicas de ensaios não-destrutivos que vistoriam materiais ou equipamentos sem a necessidade de danificá-los. Esse método constitui-se na percepção da radiação infravermelho, emitida por um corpo através de um aparelho capacitado a detectar e assimilar esse tipo de transferência de calor (MEDEIROS, 2010). Na vistoria, aplicou-se o método da Termografia passiva, técnica que se dispõe do sol como a fonte de transferência de calor.

De acordo com Moresco, E. et al (2015) a termografia infravermelha utiliza um sensor que capta a radiação no comprimento de onda infravermelho termal para a geração de imagens chamadas termogramas. Foram avaliadas as tesourinhas do eixo $L$ e $W$, das quadras 11/12 da Asa Norte eas avaliações foram realizadas com câmeras termográficas e também com a utilização de câmeras de alta resolução. A partir da técnica, foi possível identificar áreas que possuem a presença de manifestações patológicas, desde a presença de fissuras atébiodeterioração e manchas causadas por umidade.

Essa técnica vem sendo utilizada e aprimorada constantemente dentro da Engenharia e este trabalho tem como foco o cadastramento de manifestações patológicas por análise termográfica e visual de Obras de Arte Especiais (OAEs).

A imagem abaixo mostra brevemente a utilização da técnica que será abordada.

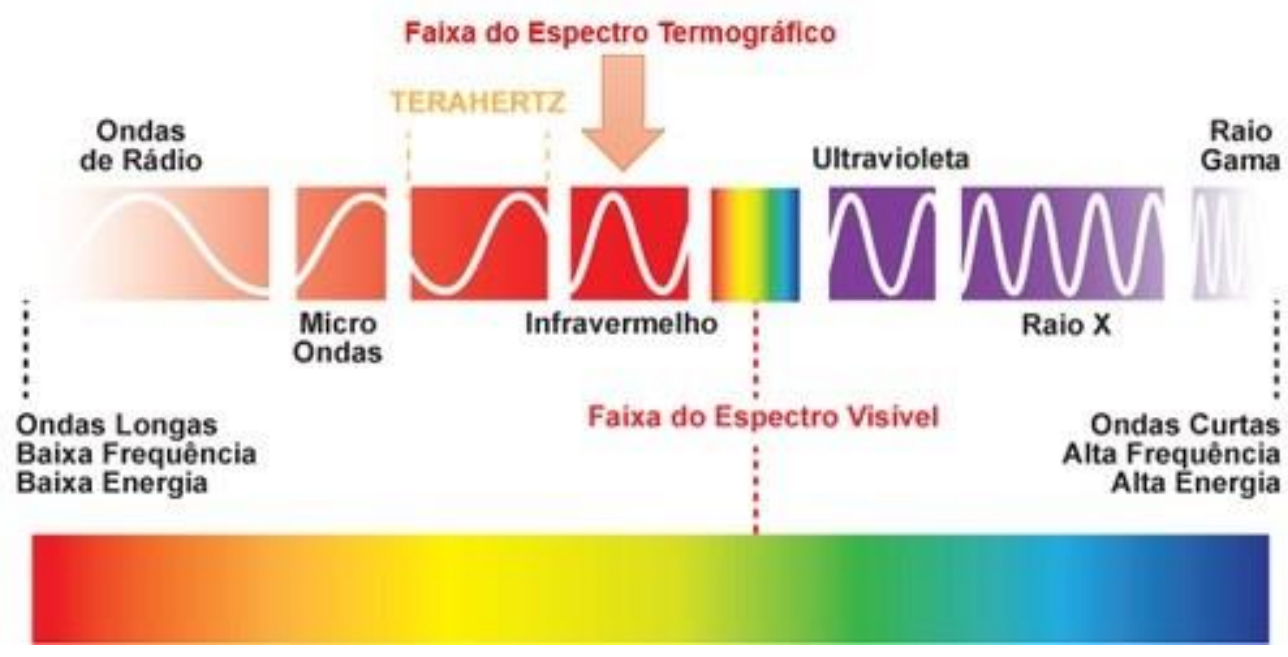

Figura 1- Método Termográfico 


\section{$\mathbf{X I X}$ \\ CIONEMI}

\subsection{OBJETIVO GERAL}

O objetivo destapesquisa é relatar os procedimentos adotados e os dados obtidos em campo na vistoria das"tesourinhas" já mencionadas neste trabalho. O foco deste trabalho é realizar um projeto Multidisciplinar de Engenharia de Manutenção, introduzindo a aplicação de câmeras termográficas para análise qualitativa identificando e cadastrando possíveis manifestações patológicas e não conformidades encontradas nos viadutos.

\subsection{OBJETIVO ESPECÍFICO}

Busca-se realizar a técnica termográfica em viadutos, abordando e incentivando o aprimoramento da utilização da mesma, para obras de arte especiais que não possuem constante incidência solar.

MATERIAIS E MÉTODOS

\subsection{LOCALIZAÇÃO}

A vistoria foi realizada no viaduto/tesoura inferior, central e superior, localizados na Asa Norte Superquadra Norte $112 / 212$. Os viadutos estão situados abaixo do Eixo Norte, uma avenida que possui bastante movimento e consequentemente gera grande quantitativo de carga. Este viaduto possui pista simples para os dois sentidos e possui acesso tanto para subir quanto para descer, sentido eixo ou sentido quadras 112 e 212.

A figura a seguir possui setas que indicam os viadutos/tesourinhas analisados.

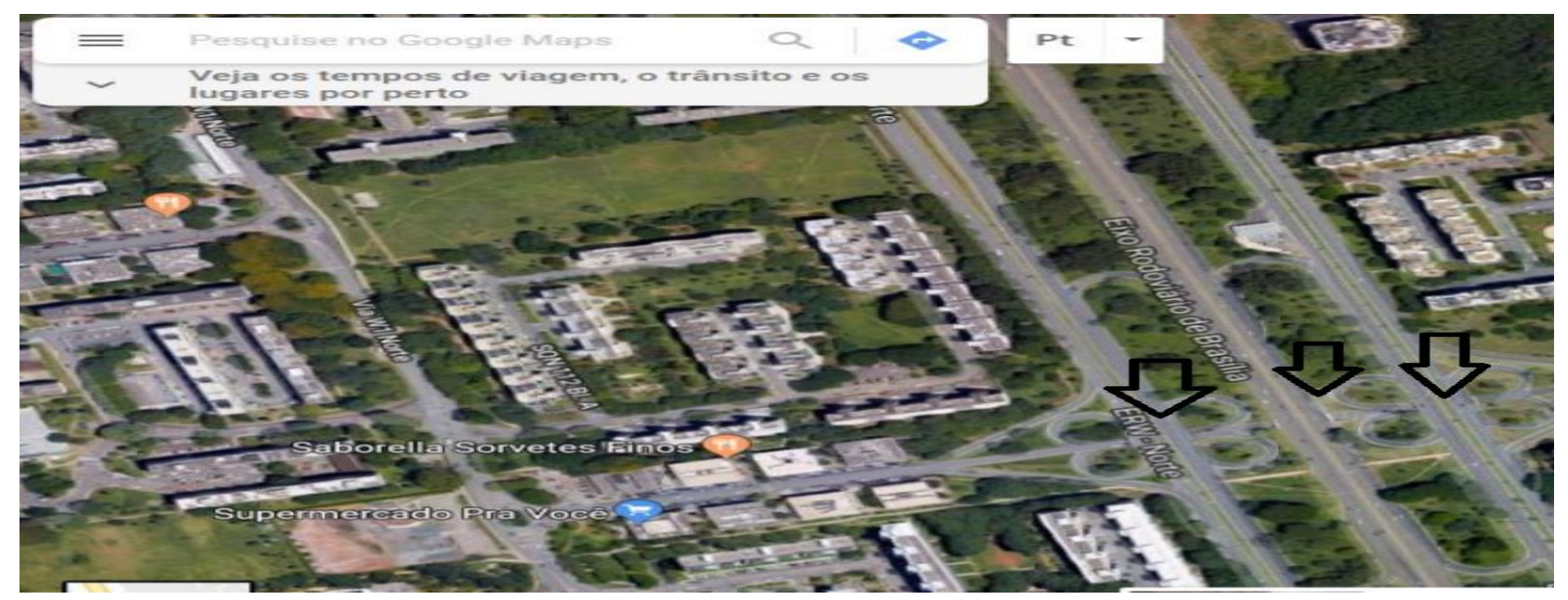

Figura 2- Setas indicando viadutos analisados 


\section{XIX \\ CIONEMI}

\subsection{EQUIPAMENTOS UTILIZADOS}

Como principal meio de análise termográfica, utilizamos os seguintes recursos:

- Flir C3

- Fluke

- FlirOne Pro

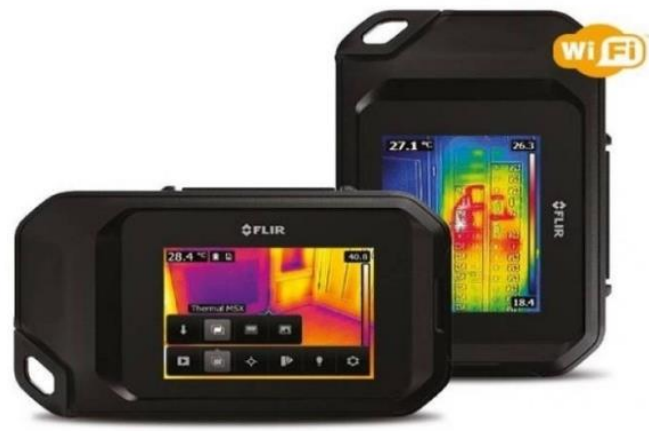

Figura 2-Flir C3

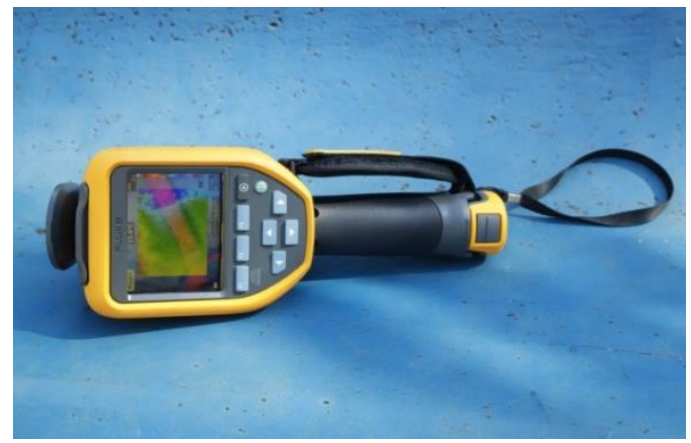

Figura 3- Fluke

\begin{tabular}{|c|c|c|c|}
\hline MARCA & Fluke & FLIR & Flir \\
\hline MODELO & TiS60 & OnePro & $\mathrm{C3}$ \\
\hline DIMENSÕES & $267 \times 101 \times 145 \mathrm{~mm}$ & $68 \times 34 \times 14 \mathrm{~mm}$ & $125 \times 80 \times 24 \mathrm{~mm}$ \\
\hline PRECISÃO & $\pm 2{ }^{\circ} \mathrm{C}$ ou $2 \%$ & $\pm 3^{\circ} \mathrm{Cou} \pm 5 \%$ & $\pm 2{ }^{\circ} \mathrm{C} \mathrm{ou}+2 \%$ \\
\hline $\begin{array}{l}\text { FAIXA DINÂMICA DE } \\
\text { CENA }\end{array}$ & $-20^{\circ} \mathrm{C}$ a $550^{\circ} \mathrm{C}$ & $-20^{\circ} \mathrm{C}$ a $400^{\circ} \mathrm{C}$ & $-10^{\circ} \mathrm{C}$ a $150^{\circ} \mathrm{C}$ \\
\hline CAPTURA DE IMAGEM & câmera5MP & $1440 \times 1080$ & $640 \times 480$ \\
\hline RESOLUÇÃO TÉRMICA & $260 \times 195$ & $160 \times 120$ & $80 \times 60$ \\
\hline $\begin{array}{l}\text { CONFIGURAÇÕES DE } \\
\text { EMISSIVIDADE }\end{array}$ & $\begin{array}{l}\text { Sim } \\
80 \%, \text { Emissividade } \\
\text { Semibrilhante: fosc } \\
\text { Brilhante: mibrilha }\end{array}$ & $\begin{array}{l}\text { Fosco:95\%, } \\
\text { 'semifosco/se } 60 \% \text {, } \\
\text { te + valor } 30 \%\end{array}$ & $\begin{array}{l}\text { Semifosco: } \\
\text { personalizado }\end{array}$ \\
\hline
\end{tabular}




\section{XIX \\ CONEMI}

Tabela 1-Especificações dos equipamentos termográficos

\subsection{CONTEXTUALIZAÇÃO}

A Termografia Infravermelha (TI) é um dos vários métodos de Ensaios Não-Destrutivos (END's), que são técnicas que inspecionam materiais ou equipamentos sem a necessidade de danificá-los, podendo ser usado nas etapas de fabricação, construção, montagem e manutenção (ABENDI, 2015).

No caso das construções, os END's podem ser usados inclusive com as estruturas em pleno funcionamento, além de garantir que manifestações patológicas possam ser detectadas em estágios iniciais (MEDEIROS, 2010).

A Termografia Infravermelha (TI) é um procedimento novo na construção civil e que se constitui na percepção da radiação infravermelha emitida por um corpo através de um aparelho capacitado a detectar e assimilar esse tipo de transferência de calor (radiação); com isso, torna-se possível a análise com precisão de algumas manifestações patológicas que ocorrem nas construções (MEDEIROS, 2010).

A inspeção termográfica é feita utilizando-se câmaras termográficas, além de termômetros de contato (que permitem a determinação da emissividade) e de medidores de radiação térmica (que são analisadores da envolvente), caso sejam necessários. Podem ser citadas diversas aplicações da TI na construção civil, tanto na detecção de manifestações patológicas que podem ser verificadas visualmente, como também, nas que ainda não são aparentes (até mesmo em problemas embrionários). Como exemplos de manifestações patológicas que o método de Tl é capaz de detectar, pode-se citar: infiltrações ou fugas de água; fendas estruturais; vazios no interior do concreto; corrosão de armaduras; etc. (MENDONÇA; AMARAL; CATARINO, 2010)

\subsection{TÉCNICA TERMOGRÁFICA}

A Técnica de Termografia Passiva é caracterizada por não possuir um estímulo "artificial" de energia, ou seja, só há absorção de energia do corpo por meio da carga solar atuante sobre o corpo. Tem um caráter mais qualitativo que a Termografia Ativa, já que apresenta indicativos de anomalias. Já a TI ativa tem como característica principal a aplicação de um estímulo energético sobre o corpo estudado. Tal estímulo pode ser aplicado tanto com uma fonte de calor quanto com uma "fonte de frio" (que remove a energia térmica do corpo). O objetivo do estímulo é gerar um diferencial térmico entre o corpo e o meio. Tem um caráter mais quantitativo que a TI passiva, uma vez que se pode medir e controlar parâmetros como fonte, tempo, intensidade e distância (MENDONÇA; AMARAL; CATARINO, 2010).

\subsubsection{APLICAÇÃO NA CONSTRUÇÃO CIVIL}




\section{$\mathrm{XIX}$ \\ CENEMI}

As aplicações da técnica de termografia infravermelha na construção civil vão desde a avaliação do desempenho e do conforto térmico das edificações até a deteç̧ão de manifestações patológicas. $\mathrm{O}$ uso da TI ainda permite uma análise térmica eficiente dos edifícios e a identificação dos sistemas que os compõe (estruturais, de vedação, elétrico, entre outros) (MENDONÇA, 2005). Utilizando a técnica termográfica infravermelha pode-se facilmente: identificar os elementos das estruturas de concreto armado das edificações, como afirmam Kersul (2014), Mendonça, Amaral e Catarino (2010) e Bauer (2013); observar algumas fissuras que se apresentam para a câmera térmica, como regiões com variação de aproximadamente $1^{\circ} \mathrm{C}$ se comparadas ao revestimento em que se encontra (FREITAS; CARASEK; CASCUDO, 2014); detectar umidade nos elementos da construção civil, antes mesmo que se tornem visíveis a olho nu (MENDONÇA; AMARAL; CATARINO, 2010).

Além da vistoria termográfica, pode-se frisar que as obras necessitam de acompanhamento constante para controle e prevenção. Para realização deste controle da estrutura, foram conceituadas e exemplificadas algumas das vistorias que devem ser adotadas pelos usuários.

\subsubsection{VISTORIA CADASTRAL}

Segundo Vitório, esse tipo de vistoria é destinado a manter atualizado o cadastro da obra, devendo ser realizada a intervalos de tempo regulares não superior a um ano. Esta vistoria também pode ser motivada por ocorrências excepcionais como levantamento de patologias aparentes ou por técnicas não destrutivas.

\subsubsection{TIPOS DE ENSAIOS}

Com filosofia dada na corrente de manutenção preditiva, as técnicas de ensaios conduzidos por inspeções são discernidas em dois principais campos, os não destrutivos e os destrutivos.

Os ensaios são dimensionados de acordo com as demandas de entendimento necessárias no processo investigativo, ou seja, com bojo no entendimento dos fenômenos do objeto de análise (FERREIRA, 2019).

\subsection{DESTRUTIVOS}

Os métodos destrutivos estão associados à coleta de amostra ou corpo de prova, normalmente seguido de análise ou ensaio laboratorial. Por ter que retirar material, esses ensaios carecem de um serviço de reconstituição do objeto para assegurar sua operacionalidade sem prejudicar sua utilização (FERREIRA, 2019). 


\section{$\mathbf{X I X}$ \\ CENEMI}

\subsection{NÃO DESTRUTIVOS}

Os métodos não-destrutivos permitem a inspeção dos elementos sem prejudicar sua utilização. Alguns métodos não-destrutivos podem empregar ultrassom, líquidos penetrantes, raios $\mathrm{x} e$ gamagrafia. Vale ressaltar que, frequentemente, estão surgindo novos métodos e novos equipamentos que se incluem nas técnicas avançadas de inspeção. (FERREIRA, 2019).

\subsubsection{VISTORIA VISUAL AÉREA}

Conforme publicado pela ABENDI em 2017 e com o avanço da tecnologia, se tornou possível a aplicação de VANT (Veículo Aéreo Não Tripulado) para a execução da inspeção visual. O aparelho é controlado remotamente por uma pessoa treinada e altamente capacitada,controlando e realizando um sobrevoosobre a estrutura com uma câmera acoplada e registrando toda a formação aeroespacial do objeto foco da inspeção.

A utilização de VANT no mercado da engenharia proporcionou uma melhor visão sistêmica de implantação das estruturas e diminuição do tempo de inspeção. Essa técnica pode ainda ser complementada com georreferenciamento e fotogrametria, possibilitando também em último caso o uso de inteligência artificial para reconhecimento de imagens, tornando o processo de catalogação das patologias mais rápido.

\subsubsection{VISTORIA VISUAL}

Como abordado por FERREIRA em 2019 a inspeção visual é uma das mais antigas atividades nos setores da indústria e da construção civil. A vistoria visual pode ser considerada o primeiro ensaio não destrutivo aplicado em qualquer tipo de peça ou estrutura.

Conforme ABENDI em 2017, a inspeção visual é um importante recurso na verificação de alterações dimensionais, padrão de acabamento superficial e na observação de descontinuidades superficiais visuais em materiais e produtos em geral, tais como trincas, corrosão deformação, alinhamento, cavidades, porosidade, montagem de sistemas mecânicos e muitos outros.

\section{RESULTADOS}

Os resultados serão divididos em três partes, pois para cada viaduto (inferior, central e superior) tem-se resultados e patologias diferentes. 


\section{XIX \\ CONEMI}

\subsection{VIADUTOINFERIOR}

As inspeções do viaduto definido como inferior começaram analisando a cortina do lado esquerdo, sentido 112 Norte. Na imagem da cortina abaixo, podemos perceber presença de umidade e consequentemente foi possível identificar armaduras expostas. A presença de eflorescência, que é causada pelo fenômeno de Lixiviação, também pode ser explicada pela presença de umidade. Já na cortina direita, o viaduto se encontrava com bueiro deteriorado, causando ineficiência do mesmo e possivelmente entupimento durante ou após precipitações, dificultando a drenagem da água e outros inúmeros problemas que a má drenagem pode causar.

A figura abaixo demonstra armadura exposta e carbonatada, perdendo sua resistência à tração e consequentemente sua função principal na estrutura.

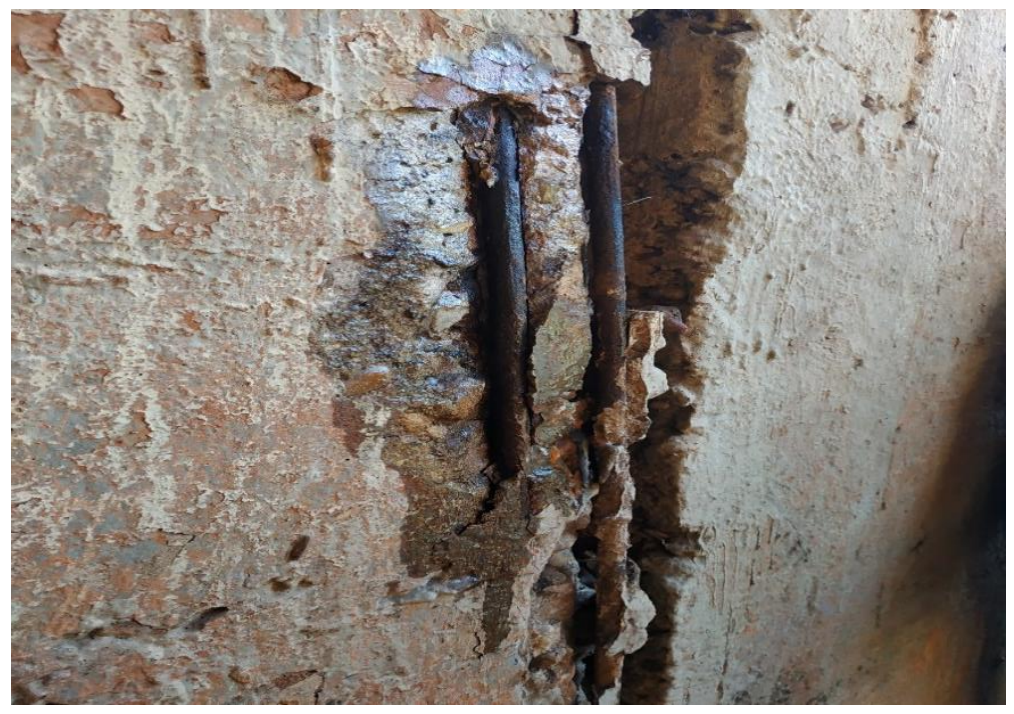

Figura 4- Armadura Exposta na Cortina

A figura a seguir demonstra a presença de eflorescência, advinda do processo de Lixiviação.
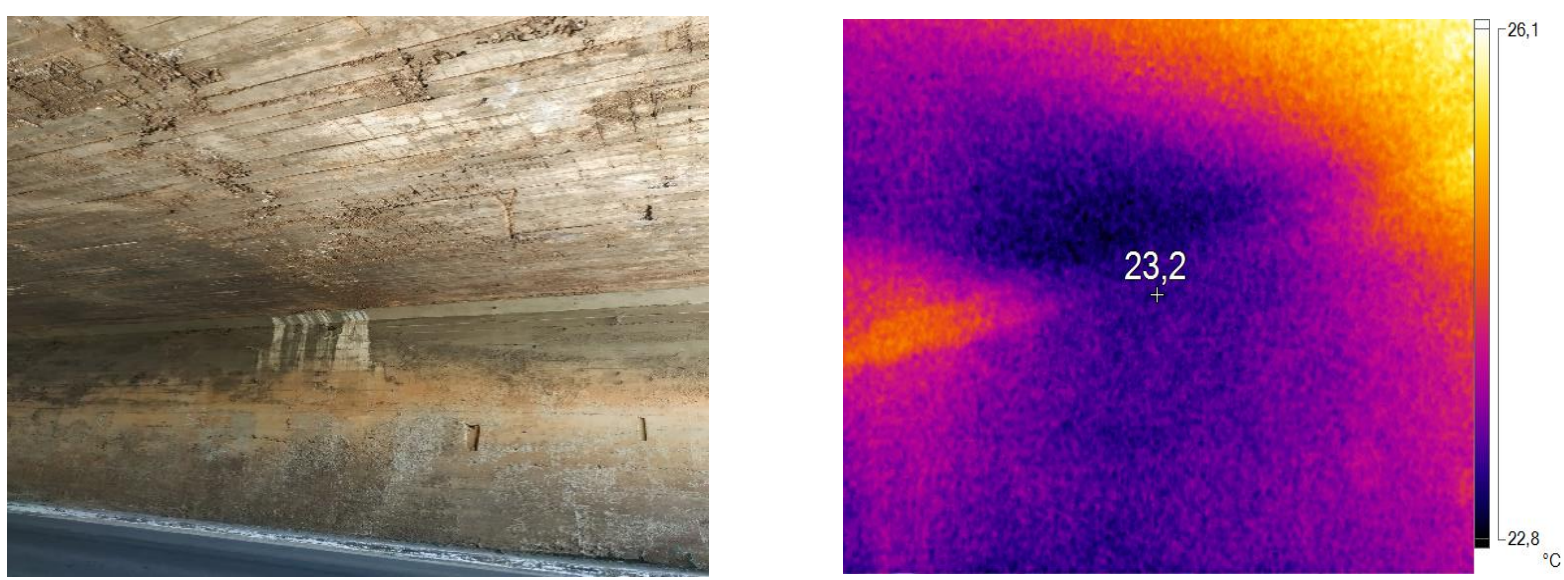


\section{XIX \\ CENEMI}

Figura 5-Eflorescência

Figura 6- Análise Termográfica

Em análises termográficas de eflorescência, pode-se identificar o diferencial térmico que indica presença de umidade. A área roxa (escura) indica possível umidade em relação a pigmentação avermelhada ou amarela.

O viaduto inferior possui infiltrações na laje, podendo ser identificadas por inspeção visual e termográfica. As imagens a seguir demonstram o problema encontrado.

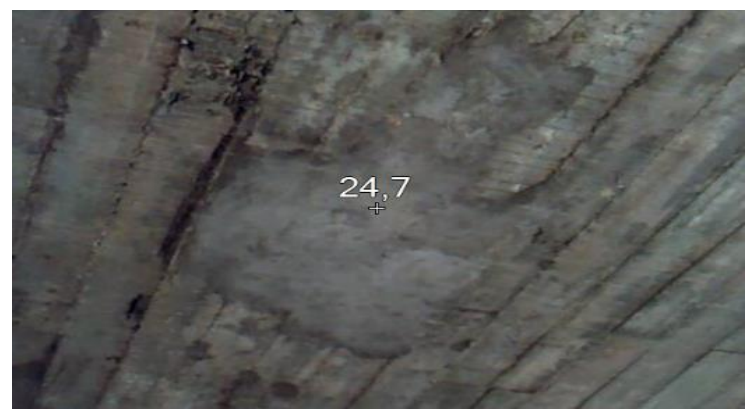

Figura 7- Análise visual (umidade)

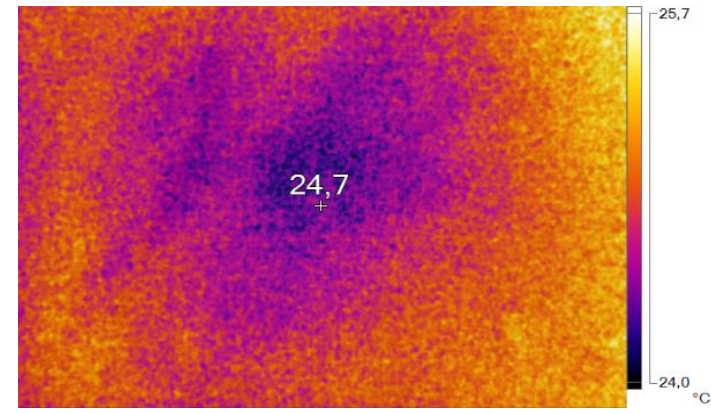

Figura 8- Análise temográfica

Também diagnosticado como um problema de funcionalidade da estrutura. A deterioração do bueiro principal pode ser percebida de forma visual, porém não é possível e nem necessário realizar a análise termográfica devido a temperatura do bueiro ser praticamente a mesma do asfalto e da área de acesso.

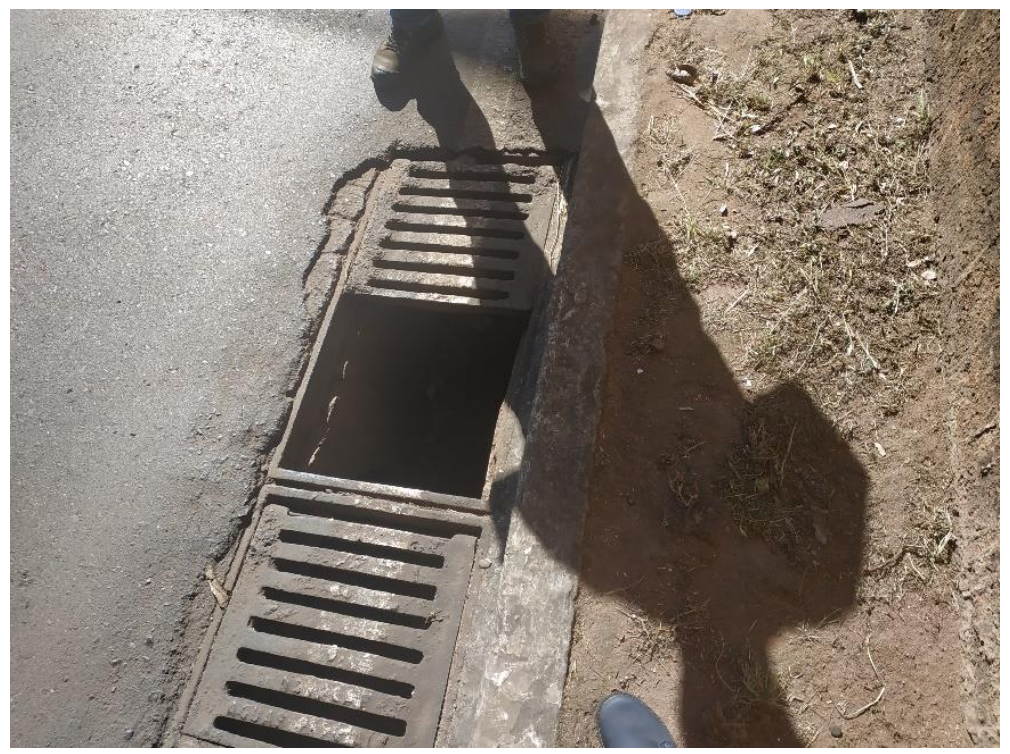

Figura 7- Deterioração do Bueiro Principal 


\section{$\mathrm{XIX}$ \\ CENEMI}

A armadura do guarda corpo se encontrava sem presença do cobrimento necessário, consequentemente exposta e corroída. Não foi possível a análise termográfica em virtude da locação do guarda corpo.

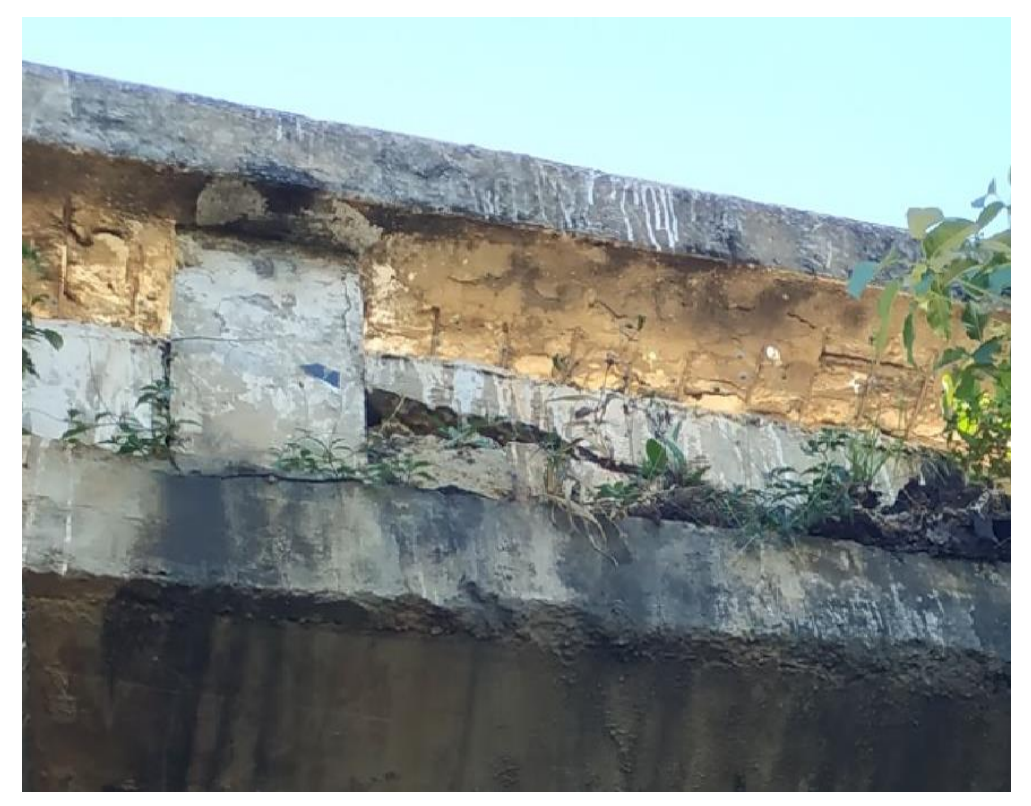

Figura 8- Guarda Corpo

\subsection{VIADUTO CENTRAL}

O viaduto central apresentou a presença de umidade como principal problema. $O$ viaduto possui a presença de vegetação, o que causa um grande problema, pois onde há vegetação, consequentemente existirá a presença de água, podendo desplacar o concreto e causar a exposição de armaduras. Como consequência, foram apresentadas algumas rachaduras que podem acarretar em desabamentos graves, por ações como a saturação do solo, o desplacamento contínuo ou fortes precipitações.

A figura a seguir mostra o crescimento de raízes dentro da peça de concreto estrutural. 


\section{$\mathrm{XIX}$ CIONEMI}

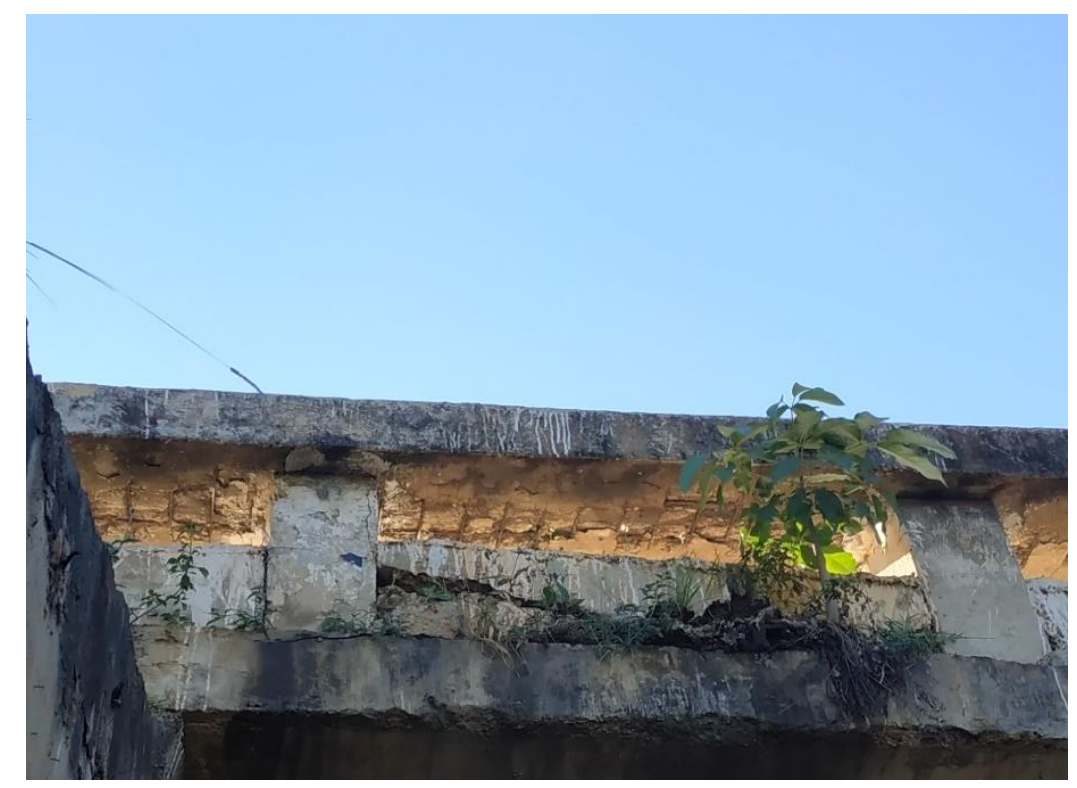

Figura 9- Vegetação no concreto estrutural

Outro fator que pode ser analisado tanto visualmente como por inspeção termográfica, foram as infiltrações nos "rodapés" do viaduto e a presença de lodo.

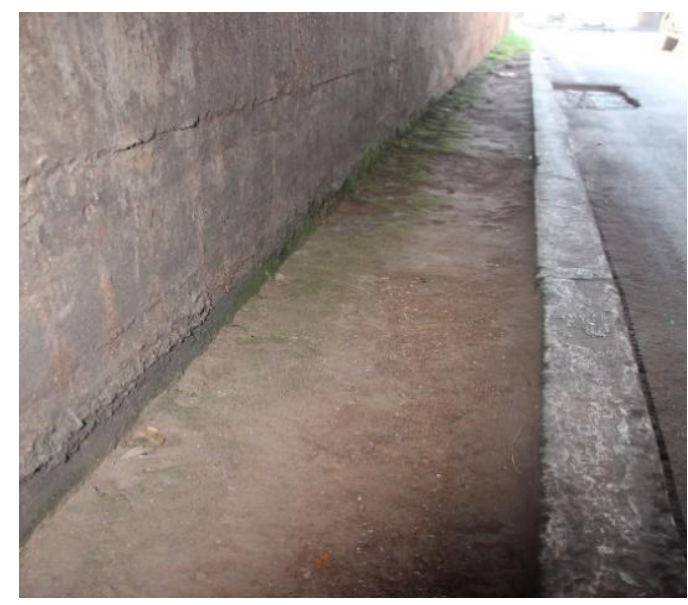

Figura 10- Inspeção Visual

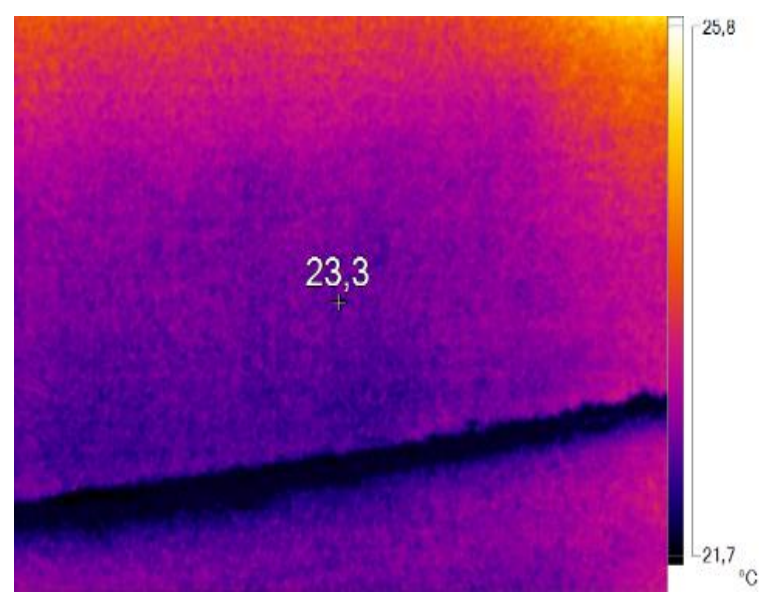

Figura 11- Inspeção Termográfica

A presença de vegetação nas cortinas e nas alas (aberturas) pode ser detectada visualmente. Com a presença da técnica termográfica podemos analisar pontualmente onde se encontram os pontos que apresentam presença de vegetação. 


\section{XIX \\ CENEMI}

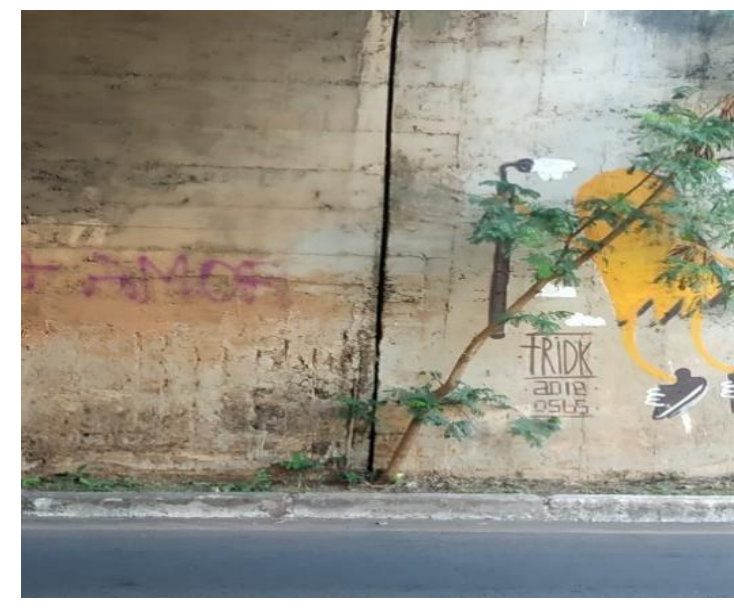

Figura 12- Exposição da armadura

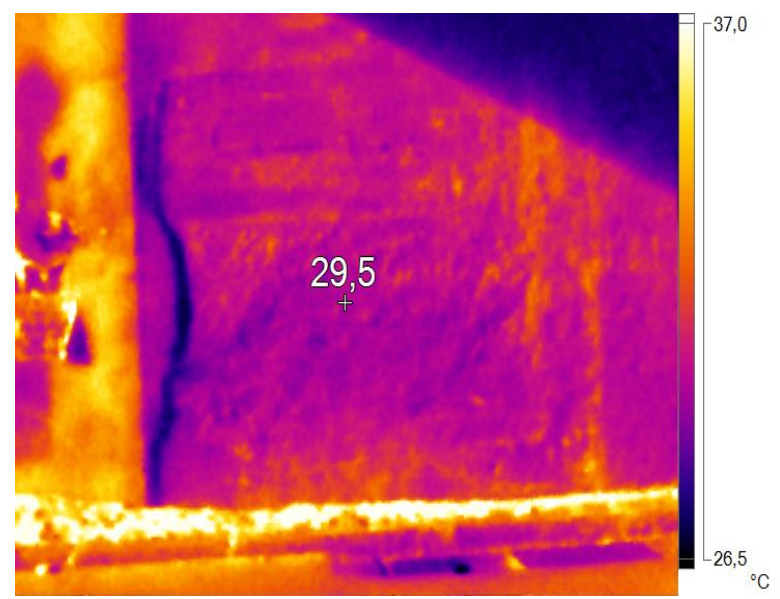

Figura 13-Inspeção Termográfica (vegetação)

\subsection{VIADUTO SUPERIOR}

O viaduto definido como superior é o que maior apresenta exposição da armadura da laje, por isso grandes vãos estão expostos, sofrendodesplacamento e consequentemente a corrosão do aço. Este fato pode estar diretamente ligado a locação de um canteiro de grama em cima do viaduto, exatamente onde as armaduras estão expostas.

A corrosão, por ser um processo eletroquímico das reações de oxirredução, ou seja, transferência de elétrons entre os átomos, em geral ocorre pela presença de oxigênio, porém alguns fatores podem acelerar o processo, como por exemplo a presença de gás carbônico $\left(\mathrm{CO}_{2}\right)$.

Como o viaduto está constantemente sofrendo como gás carbônico emitido por veículos, o aço da laje, o qual está mais próximo desses gases, é o primeiro a sofrer corrosão quando o concreto desplaca e deixa de contribuir como proteção física/química para o aço.

A imagem a seguir demonstra o vão em que a peça diminuiu sua área de concreto e deixou a armadura exposta à umidade. 


\section{XIX \\ CENEMI}
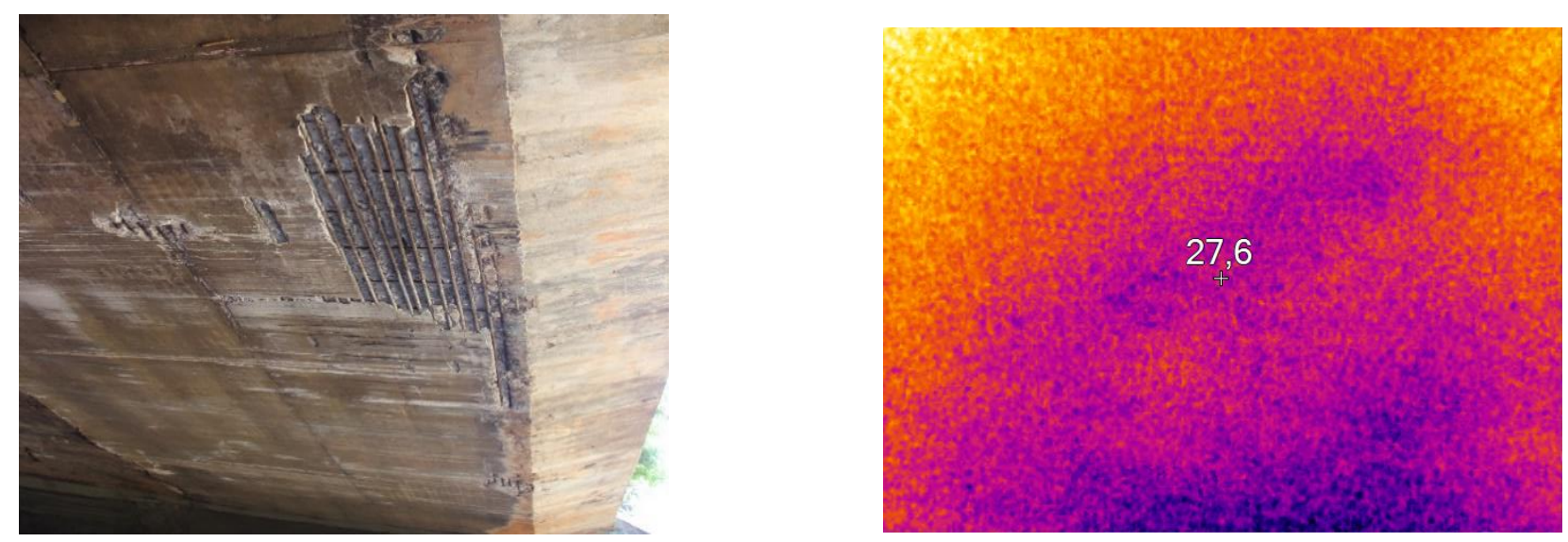

Figura 14- Análise visual

Figura 15- Análise termográfica

Por conta de a armadura exposta situar próximo ao término do viaduto, não foi possível captar muitas variações térmicas em imagens termográficas, porém como toda a laje sofreu este tipo de problema, as fotos a seguir mostram a repetição desta patologia em menores áreas espalhadas por esta mesma laje.

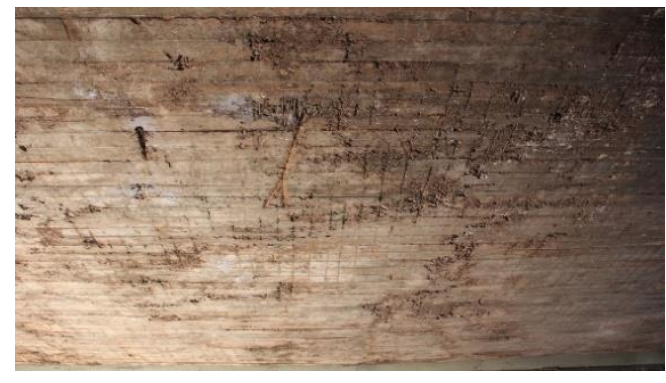

Figura 16- Armadura exposta na laje

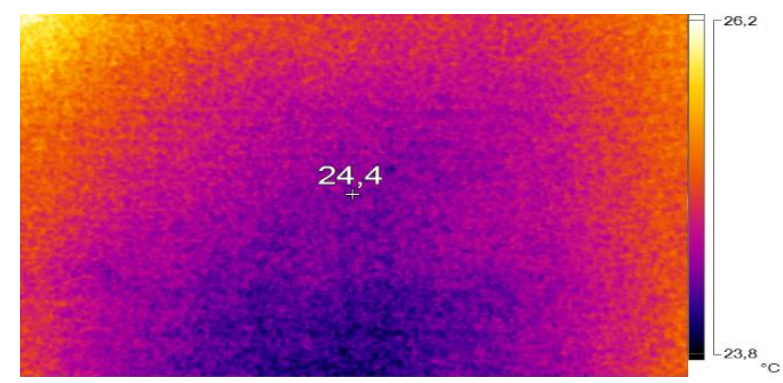

Figura 17- Presença de umidade na armadura exposta

O viaduto superior também apresentou armadura exposta no seu "rodapé" diante quase toda sua extensão.

A imagem a seguir demonstra a inspeção visual desta armadura exposta, possivelmente por infiltrações e grande presença de umidade, detectando variações de temperatura exatamente onde as armaduras estão expostas e resultando em corrosão da armadura. 


\section{XIX \\ CENEMI}

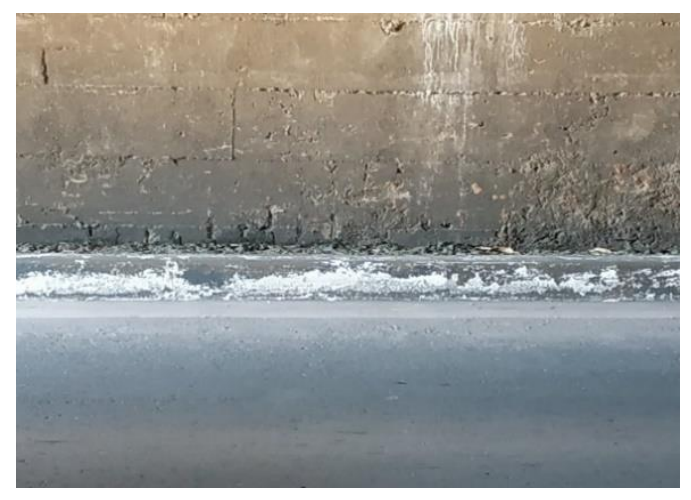

Figura 18- Armadura exposta no "rodapé"

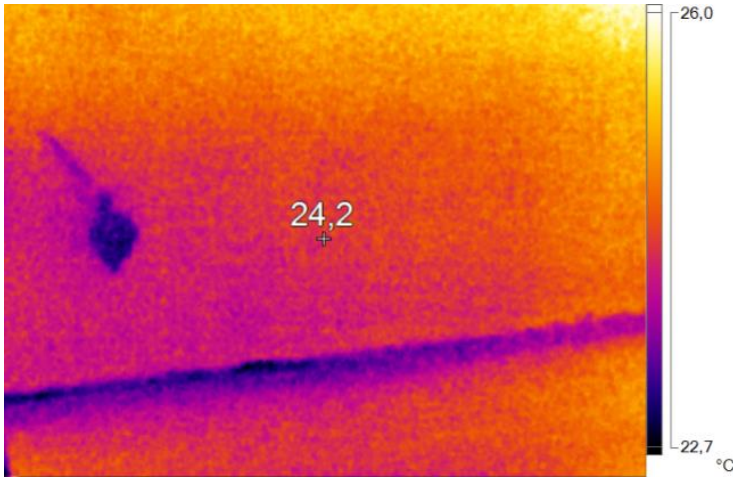

Figura 19- Inspeção termográfica no "rodapé"

\section{CONCLUSÃO}

A estrutura de concreto armado do viaduto superior se destaca negativamente por possuir maior quantitativo de armadura exposta, por isso o aço se encontra corroído perdendo sua funcionalidade mecânica à tração. Esses fatores demonstram que este pode ser considerado o viaduto mais preocupante e que necessita de tratamento especial em suas patologias. Por não possuir revestimento cerâmico, o concreto teve maior facilidade para se desplacar por efeitos naturais, choques mecânicos/colisões ou até mesmo por agentes agressivos do meio.

Os outros dois viadutos, central e inferior, também precisam de tratamento, porém na inspeção visual e termográfica não se pode afirmar que a estrutura possui riscos estruturais, porque para realizar esta análise complexa é preciso realizar diversos ensaios químicos, físicos e mecânicos, que demonstrem que a umidade pode estar corroendo internamente a estrutura de concreto armado, seção que não pode ser verificada por inspeção visual.

Pode-se concluir que os principais problemas que causaram o desplacamento do concreto estão diretamente ligados a umidade. A ausência de pingadeira pode justificar a infiltração de água nas alas, econsequentemente o crescimento de vegetação e outros inúmeros problemas que já foram detalhados neste relatório.

Este trabalho colaborou com a conscientização e motivação para realização de vistorias e análises técnicas em estruturas de OAEs.

A engenharia brasileira atualmente sofre com falta de manutenções preventivas, por conta deste motivo este presente trabalho também espera colaborar com o aumento gradativo de incentivo para vistorias preventivas e preditivas. 


\section{$\mathbf{X I X}$ \\ CIONEMI}

\subsection{DISCUSSÕES}

Em linhas gerais, o que se pode sugerir em termos de preservação patrimonial e segurança à sociedade,é a adoção de Plano de Manutenção, Operação e Controle.

Existem poucas leis relacionadas a manutenção, sendo assim o serviço passa a ser de pouca importância para muitos usuários que não se importam ou até mesmo desconhecem de sua relevância. A elaboração de leis rígidas e práticas mais abrangentes em torno do exercício da manutenção seria de grande valia para melhora e duração das estruturas.

Sugere-se inclusive a criação de um banco de dados de monitoramento consultáveis, inspeções periódicas, intervenções e projetos atualizados, haja vista que essas informações podem contribuir para a formação de uma comunidade dedicada ao estudo e preservação de nossas obras de arte especiais e monumentos, reduzindo custos de levantamentos e acompanhamento por parte das autoridades.

Como meio de contribuição para disseminação cultural de manutenções, uma alternativa benéfica sera o incentivo para a formação de engenheiros especialistas em manutenção de obras.

A lei de evolução dos custos, conhecida como Lei de Sitter, mostra que os custos de correção crescem segundo uma progressão geométrica de razão cinco, conforme a figura abaixo.

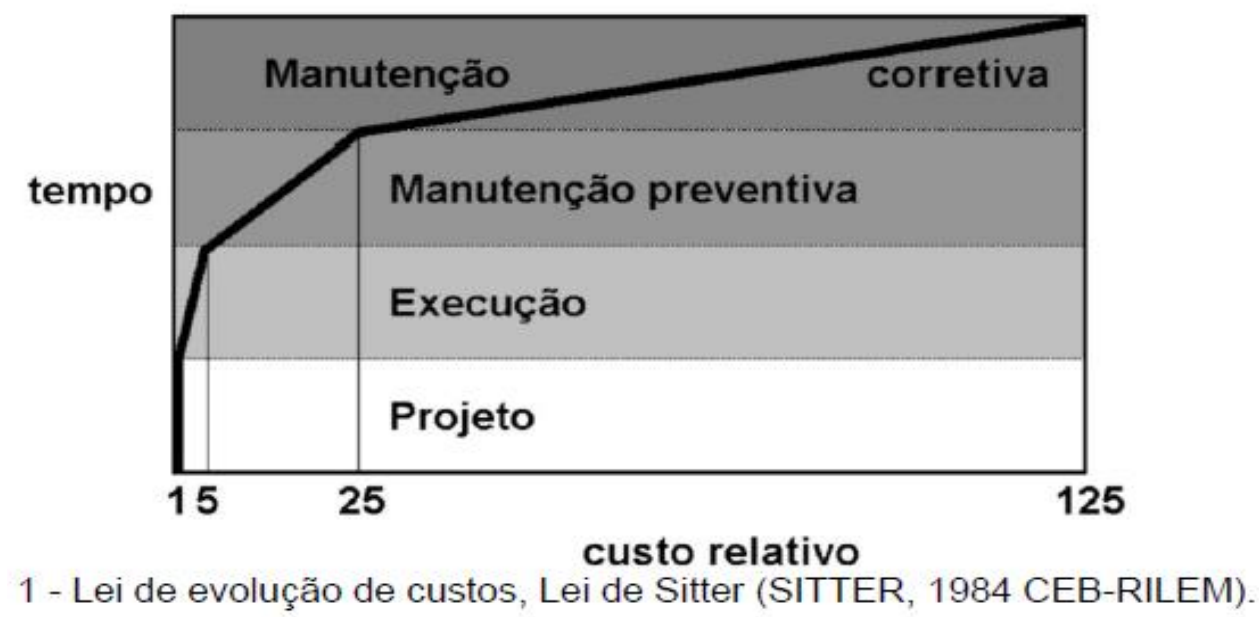

Figura 20- Lei de Evolução de custos

Como pode-se notar neste gráfico apresentado, os custos de manutenção corretiva ultrapassam o valor real do recurso disponibilizado para construção. A manutenção deve então seguir um padrão de prevenção e não de correção, com intuito de evitar desperdício de recursos, tempo e problemas durante a restauração da obra. 


\section{$\mathbf{X I X}$ \\ CENEMI}

\section{AGRADECIMENTOS}

Agradecemos ao Gutemberg Rios, Presidente da ABEMEC-DF e ao Professor Henrique Nery, por nos proporcionar a participação no evento TERMODAN. Agradecemos também pelo apoio da Equipe TERMODAN, que tem nos auxiliado no decorrer do projeto.

Agradecemos a Fernanda Mendes pela a disponibilidade e por todo o apoio na elaboração do artigo, nos auxiliando na formatação e revisão dos conceitos.

\section{REFERÊNCIAS}

ABENDI. "Associação Brasileira de Ensaios Não destrutivos,." Técnicas e Ferramentas para Ensaios Não Destrutivos. São Paulo, Novembro de 2017.

BARREIRA, E.; FREITAS, V. P. "Evaluation of building materials using infrared thermography." Construction and Building Materials, v. 21, p. 218-224,. Amsterdam, 2007.

BAUER, ELTON, e FRANZ E CASTELO BRANCO LEAL. "CONDICIONANTES DAS MEDIÇÕES TERMOGRÁFICAS PARA AVALIAÇÃO DA TEMPERATURA EM FACHADAS." X SIMPÓSIO BRASILEIRO DE TECNOLOGIA DAS ARGAMASSAS. Fortaleza, maio de 2013.

Ferreira, João Vitor De Souza. "INSPEÇÃO E MONITORAMENTO DE OBRAS DE ARTE ESPECIAIS COM VISTA A MANUTENÇÃO PREDITIVA." INSPEÇÃO E MONITORAMENTO DE OBRAS DE ARTE ESPECIAIS COM VISTA A MANUTENÇÃO PREDITIVA. Rio de Janeiro, Janeiro de 2018.

Gonçalves, Eduardo Albuquerque Buys. "ESTUDO DE PATOLOGIAS E SUAS CAUSAS NAS ESTRUTURAS DE CONCRETO ARMADO DE OBRAS DE EDIFICAÇÕES.” UFRJ/ ESCOLA POLITÉCNICA. Rio de Janeiro, 2015.

GONÇALVES, T. “ Estado da Arte da Dissertação de Sistemas de Energia e Máquinas Eléctricas com recurso a Termografia." Dissertação de Mestrado. Porto, 2011.

Mendonça, Luís Viegas. "Termografia por Infravermelhos Inspeç̧ão de Betão ." Publicado na revista Engenharia \& Vida, no 16, Setembro 2005, pp. 53-57. julho de 2005.

PIANCASTELLI, E. M. "Patologia, Recuperação e Reforço de Estruturas de Concreto Armado." Apostila para Curso de Extensão. Belo Horizonte: Ed. Depto. Estruturas da Escola de Engenharia da UFRG, 1997. 


\section{XIX \\ CENEMI}

Vitório, José Afonso Pereira. "Vistorias, Conservação e Gestão de Pontes e Viadutos de Concreto." Anais do 48 Congresso Brasileiro do Concreto, Setembro de 2006.

BAUER, E.; CASTRO, E.K.; OLIVEIRA FILHO, A.H.; PAVÓN, E.A. (2014). Critérios para aplicação da termografia de infravermelho passiva como técnica auxiliar ao diagnóstico de patologias em fachadas de edifícios. 1ㅇ Encontro Luso-Brasileiro de Degradação em Estruturas de Concreto Armado. Salvador, BA. 10p.

BAUER, L.A.F. Materiais de Construção. (2008). Rio de Janeiro, RJ: LTC - Litros Técnicos e Científicos Editora S.A, 5a Ed Revisada. Volume 1, 471 páginas.

TAKEDA, O.T.; MAZER, W. (2018). Potencial da análise termográfica para avaliar manifestações patológicas em sistemas de revestimentos de fachadas. Revista ALCONPAT Internacional, Volume 8, Número 01. 12p.

PAVON, E. (2017). Critérios e padrões de comportamento para avaliação de descolamentos cerâmicos com termografia de infravermelho. Tese de Doutorado, Publicação E.TD-6A/17, Departamento de Engenharia Civil e Ambiental, Universidade de Brasília, Brasília- DF, 250p. 